Case Reports in
Gastroenterology
Case Rep Gastroenterol 2021;15:53-61

DOI: 10.1159/000510932

Published online: January 25, 2021

(C) 2021 The Author(s)

Published by S. Karger AG, Basel www.karger.com/crg

This article is licensed under the Creative Commons Attribution-NonCommercial 4.0 International License (CC BY-NC) (http://www.karger.com/Services/OpenAccessLicense). Usage and distribution for commercial purposes requires written permission.

\title{
Biliary Peritonitis Caused by Spontaneous Bile Duct Rupture in the Left Triangular Ligament of the Liver after Endoscopic Sphincterotomy for Choledocholithiasis
}

\author{
Taro Fukui ${ }^{a}$ Takeshi Chochi ${ }^{\mathrm{a}}$ Toru Maeda ${ }^{\mathrm{a}}$ Chunyong Lee ${ }^{\mathrm{a}}$ \\ Yohnosuke Wada ${ }^{a}$ Masaki Ohashi ${ }^{a}$ Jun Tashiro ${ }^{b}$ Masahiro Arai ${ }^{b}$ \\ Morito Kurata $^{c}$ Takayoshi Yoshida $^{a}$ Fumio Konishi ${ }^{a}$
}

aSurgery Division, Nerima Hikarigaoka Hospital, Tokyo, Japan; bGastroenterology Division, Nerima Hikarigaoka Hospital, Tokyo, Japan; 'Department of Comprehensive Pathology, Graduate School of Medical and Dental Sciences, Tokyo Medical and Dental University, Tokyo, Japan

\section{Keywords}

Spontaneous rupture - Biliary peritonitis - Appendix fibrosa hepatis - Left triangular ligament . Endoscopic sphincterotomy

\begin{abstract}
Spontaneous bile duct rupture is a rare condition in adults, with only 70 cases reported. Increased bile duct wall pressure may lead to rupture and biliary peritonitis. In this patient, the bile duct ruptured in the hepatic left triangular ligament. A 91-year-old man underwent endoscopic retrograde cholangiopancreatography for choledocholithiasis and endoscopic retrograde biliary drainage (ERBD) placement. One week later, removal of the ERBD and common bile duct stones and an endoscopic sphincterotomy (EST) were performed. Four days later, the patient had abdominal pain, increased inflammatory reaction, and jaundice. Abdominal computed tomography showed ascites, bile duct dilatation and fluid collection under the liver (10
\end{abstract}

\begin{tabular}{ll}
\hline & Taro Fukui \\
& Surgery Division \\
& Nerima Hikarigaoka Hospital \\
& $2-11-1$ Hikarigaoka, Nerima-ku, Tokyo 179-0072 (Japan) \\
t-fukui@jichi.ac.jp
\end{tabular}




\section{Case Reports in Gastroenterology}

Case Rep Gastroenterol 2021;15:53-61 DOI: $10.1159 / 000510932$

(c) 2021 The Author(s). Published by S. Karger AG, Basel www.karger.com/crg

Fukui et al:: Spontaneous Bile Duct Rupture in the Left Triangular Ligament after EST

$\mathrm{cm}$ in diameter). Emergency surgery was performed to drain the fluid. On laparotomy, encapsulated biliary ascites was seen. To search for the site of the leak, after cholecystectomy, a tube (C-tube) was inserted into the common bile duct via cystic duct stump. Because of uncontrollable bleeding, after packing with surgical gauze, the operation was temporarily stopped. The next day, reoperation was performed. Intraoperative cholangiography with contrast dye revealed the perforation site in the left triangular ligament and a partial resection was performed. Bile excretion from the C-tube was subsequently observed, but the patient's jaundice did not improve. Although endoscopic retrograde cholangiopancreatography revealed that the EST site was normal, ERBD was placed again, and the jaundice gradually improved. Although EST was performed in this case, biliary peritonitis resulting from spontaneous bile duct rupture occurred. This case was very informative because biliary perforation may occur even after EST.

(C) 2021 The Author(s)

Published by S. Karger AG, Basel

\section{Introduction}

Bile duct rupture is commonly caused by iatrogenic factors such as surgery, endoscopic and percutaneous transhepatic biliary intervention, or abdominal trauma [1]. Spontaneous bile duct rupture is a rare condition in adults that was first described by Freeland in 1882 [2]. Only about 70 cases have been reported so far $[1,3,4]$. On the other hand, in children, it is not comparatively rare because of congenital abnormalities in the pancreatobiliary ductal system [5]. Intrahepatic bile duct rupture appears to be rarer than extrahepatic bile duct rupture [4]. An increase in ductal pressure caused by obstructions or erosion of gallstones, choledocholithiasis, hepatolithiasis, and tumors or necrosis of the biliary duct wall may lead to rupture and subsequent biliary peritonitis [6]. We present a case of a patient with spontaneous rupture of the aberrant bile duct in the left triangular ligament (LTL) of the liver and biliary peritonitis after an endoscopic sphincterotomy (EST) for choledocholithiasis. An urgent surgical intervention was needed to control the biliary peritonitis. Acute increase in biliary pressure after EST was considered to cause spontaneous rupture of the bile duct. This case was informative because the perforation site (aberrant bile duct) and timing of the rupture (after EST) were rare and instructive.

\section{Case Presentation}

A 91-year-old man presented with abdominal pain in the right upper quadrant. His medical history included chronic pancreatitis, chronic atrial fibrillation, and angina pectoris. He took apixaban (a factor Xa inhibitor, which is a direct oral anti-coagulant [DOAC]) for atrial fibrillation. His laboratory data showed inflammatory reaction (white blood cells [WBCs], $10,200 / \mu \mathrm{L}$; C-reactive protein [CRP], $3.34 \mathrm{mg} / \mathrm{dL}$ ) and an increase in hepatobiliary enzyme and serum amylase levels. On his abdominal computed tomography (CT) scan, gallbladder stones and pancreatic stones, which likely resulted from chronic pancreatitis, and an increase in fat density around the pancreas were observed. He was diagnosed with acute exacerbation of chronic pancreatitis and immediately admitted to our institution where he was treated with fasting and a drip infusion. His symptoms disappeared and food intake resumed on day 4 after admission. The patient's laboratory test results showed a sustained increase in hepatobiliary

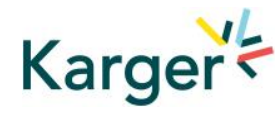




\section{Case Reports in Gastroenterology}

Case Rep Gastroenterol 2021;15:53-61

DOI: $10.1159 / 000510932$

(c) 2021 The Author(s). Published by S. Karger AG, Basel www.karger.com/crg

Fukui et al:: Spontaneous Bile Duct Rupture in the Left Triangular Ligament after EST

enzymes and amylase (Fig. 1). On day 7, magnetic resonance cholangiopancreatography showed possible tiny biliary stones in the distal bile duct. Antibiotics (cefmetazole) were started. On day 11, ERCP revealed CBD stones, and an ERBD plastic stent was inserted (Fig. 2a).

Although EST was performed for the common bile duct, the patient's laboratory test results remained in the abnormal range (Fig. 1). On day 16, the inflammatory reaction was somewhat decreased (WBCs, 12,600/ $\mu \mathrm{L} ; \mathrm{CRP}, 1.54 \mathrm{mg} / \mathrm{dL}$ ). On day 17 (1 week after the initial ERCP), EST and removal of bile stones were performed and the ERBD was removed (Fig. 2b). On day 18, food intake and DOAC resumed. On day 19, he complained of abdominal pain. An abdominal CT scan was performed to further investigate his symptoms and the elevated hepatobiliary enzymes (Fig. 1). The CT results showed retention of contrast medium in the gall bladder and CBD as well as fluid collection (approximately $5 \mathrm{~cm}$ in diameter) in the subhepatic area of the lateral segment. On day 21, his abdominal pain recurred. The patient's laboratory data showed that inflammatory markers were elevated (WBCs, 22,400/ $\mu \mathrm{L}$; CRP, $29.38 \mathrm{mg} / \mathrm{dL}$ ). His abdominal CT scan showed fluid collection that was approximately $10 \mathrm{~cm}$ in diameter in the sub-hepatic area, which was larger than that of 2 days previously, dilatation of biliary tract and gall bladder, and ascites (Fig. 3a). Perforation of the biliary tract associated with ERCP was suspected. His vital signs were unstable and he was managed in the intensive care unit. Emergency surgery was planned to drain the fluid. On the preoperative coagulation screening, prothrombin time-international normalized ratio (PT-INR) was prolonged to 9.34, which was likely because of a biliary obstruction and DOAC use. On laparotomy, biliary ascites encapsulated by the liver, stomach, and omentum was observed, which suggested a bile leak. After aspirating the biliary ascites, cholecystectomy was performed and a plastic tube (C-tube) was inserted into the CBD via the cystic duct stump to search for the site of the bile leak. Intraoperative cholangiography with X-ray contrast medium (meglumine sodium amidotrizoate) revealed no outflow into the duodenum, which suggested an obstruction of the papilla of Vater (Fig. 3b). Dye contrast with indigo carmine revealed a leak at the periphery of the lateral hepatic segment, which suggested a bile duct rupture that was caused by the increased intra-biliary pressure. Despite administering blood transfusions (fresh frozen plasma [FFP], 14 units; red blood cells [RBC], 6 units) and vitamin K, bleeding mainly from the gallbladder bed was difficult to control and blood pressure could not be maintained. Surgical gauze was packed at the bleeding site and in the abdominal cavity to terminate the operation. After administration of FFP, RBC, and vitamin K, PT-INR improved to 1.65 the next day. Reoperation was then performed. With dye injection through the C-tube, the site of the bile leak was identified at the periphery of the lateral hepatic segment, which was thought to be the LTL, and partial hepatic resection by ligation was performed with adequate abdominal irrigation and insertion of drains into the abdominal cavity (Fig. 3c). Bile excretion (approximately $150 \mathrm{~mL}$ ) was observed daily from the C-tube, but jaundice did not improve (Fig. 1). On postoperative day 5, ERCP was performed again. Although the site of EST looked normal, ERBD was placed again (Fig. 2c). Jaundice then gradually improved (Fig. 1). Pathological findings in the surgical specimen included bile ducts, arteries, and veins in a fibrous connective tissue with neutrophil infiltration and fibrin deposition in the surrounding area. The bile duct wall showed a partial defect, which was assumed to be a perforation site. There was no significant finding that suggested bile duct fragility. Liver tissue was not detected in the specimen. Based on the pathological findings, the remnant bile ducts in the appendix fibrosa hepatis (AFH) perforated spontaneously because of increased intraductal pressure in the bile duct (Fig. 3d). During his postoperative course, the patient had respiratory distress syndrome and accompanying multiple

\section{Karger'=}




\section{Case Reports in Gastroenterology}

Case Rep Gastroenterol 2021;15:53-61

DOI: $10.1159 / 000510932$

(c) 2021 The Author(s). Published by S. Karger AG, Basel www.karger.com/crg

Fukui et al.: Spontaneous Bile Duct Rupture in the Left Triangular Ligament after EST

organ failure. He also had liver dysfunction, recurrent jaundice, and renal dysfunction that required continuous hemodialysis. He died on postoperative day 48.

\section{Discussion}

In this case, spontaneous bile duct rupture occurred even after EST for choledocholithiasis. Spontaneous rupture of the bile duct is a disease that occurs without any traumatic or iatrogenic injury [3]. In this case, CBD stone removal by ERCP might be a trigger, and there were some iatrogenic factors. In a typical iatrogenic case, the bile duct is directly damaged by treatment or the surgical procedure, so we classified this case as a spontaneous rupture. Spontaneous rupture of the intrahepatic biliary duct is comparatively rare in adults. However, in children, the incidence is relatively high because of congenital abnormalities in the pancreatobiliary ductal system [5]. The factors that are involved include ischemia, elevated pressure within bile ducts, congenital weakness of the bile duct wall, and pancreaticobiliary reflux [3, $5,7]$. A total of $70 \%$ of these cases are thought to be related to choledocholithiasis [8]. Intrahepatic bile duct ruptures of the left lobe are more frequent than that of the right lobe because bile ducts are located superficially [9]. In this case, the bile duct that was located in the LTL was ruptured. The LTL has a long free edge that extends from the lateral extremity of the left liver lobe to the diaphragm. Ferrein was first to describe aberrant bile ducts in the free edge, and he also called them appendix fibrosa hepatis (AFH) [10]. AFH was found in $89 \%$ of Chinese and $80 \%$ of Canadian patients in the proximal one-third of the LTL. There are two theories about the origin of an aberrant bile duct: it occurs by a reduction of the hepatic parenchyma or by cessation of bile duct development, and the former theory is preferred [11]. The free edge of the hepatic LTL is developed by between 3 weeks and 2 years of age. AFH is not found during this period, but it was reported in a 4-year-old patient [10]. Champetier et al. [12] reported several cases of spontaneous biliary peritonitis that was caused by the rupture of an aberrant bile duct in the free edge of the LTL. In this case, although EST was performed for choledocholithiasis, the increase in the intra-ductal pressure in the bile duct that was caused by obstruction of the papilla of Vater led to the rupture of the peripheral "natural-born" bile duct.

Additionally, in our patient, jaundice worsened during the postoperative period despite biliary drainage via a C-tube. In the postoperative ERCP, the EST site looked normal. However, reinsertion of the ERBD tube for CBD via the papilla of Vater improved the jaundice. There was a report of biliary obstruction in the papilla of Vater after EST in a patient with paraduodenal diverticulum [13]. There was no paraduodenal diverticulum in our patient. Considering the risk factors for obstruction of the papilla of Vater after endoscopic intervention for the hepato-biliary-pancreatic (HBP) system, those of post-ERCP pancreatitis (PEP) could be extrapolated because PEP is mainly caused by obstruction of the papilla of Vater. Among the risk factors that are mentioned in the European Society of Gastrointestinal Endoscopy guidelines, previous pancreatitis is a patient-related factor that corresponded to this case [14].

Preoperative diagnosis of spontaneous biliary duct ruptures, which present with acute abdominal pain resulting from localized or generalized biliary peritonitis, is problematic. Preoperative diagnosis of spontaneous bile duct rupture is challenging despite advances in the diagnostic procedure. When the leak cannot be visualized macroscopically, intraoperative cholangiography following cholecystectomy is considered to be useful, which occurred in our case.

\section{Karger'=}




\section{Case Reports in Gastroenterology}

\begin{tabular}{l|l}
\hline Case Rep Gastroenterol 2021;15:53-61 \\
\hline DOI: 10.1159/000510932 & $\begin{array}{l}\text { ○ 2021 The Author(s). Published by S. Karger AG, Basel } \\
\text { www.karger.com/crg }\end{array}$ \\
\hline
\end{tabular}

Fukui et al.: Spontaneous Bile Duct Rupture in the Left Triangular Ligament after EST

In this patient, abnormal coagulation was observed. The causes were assumed to be antibiotics for pancreatitis, a biliary tract obstruction, and DOAC use. DOAC may cause severe coagulation system abnormalities [15]. Before invasive intervention, adequate coagulation screening and anti-coagulation agents or blood transfusion is required.

Spontaneous bile duct rupture occurred even after EST for choledocholithiasis. Removal of ERBD was performed at the same time as EST at 1 week after the primary ERCP in this patient. In patients with a medical history of HBP disease or a previous HBP system intervention, papilla of Vater obstruction should be considered. Extension of the period for ERBD insertion might be considered in patients with such risk factors.

In conclusion, we experienced a case of fatal, spontaneous rupture of the aberrant bile duct in the LTL, which is called AFH, and biliary peritonitis. The possibility of the papilla of Vater obstruction after EST should always be kept in mind.

\section{Acknowledgements}

The authors thank H. Yui and K. Emi for assistance with the patient's treatment. We also thank Jodi Smith, PhD, from Edanz Group (https://en-author-services.edanzgroup.com/) for editing a draft of the manuscript.

\section{Statements of Ethics}

The authors have no ethical conflicts to disclose. Informed consent for publication including images was obtained from the family of the presented patient. The research was conducted ethically in accordance with the World Medical Association Declaration of Helsinki.

\section{Conflict of Interest Statement}

The authors have no conflicts of interest to declare.

\section{Funding Sources}

This work received no funding.

\section{Author Contributions}

T. Fukui, T. Chochi, T. Yoshida, and T. Maeda performed the patient's operation; T. Fukui reviewed the literature and contributed to manuscript drafting; J. Tashiro mainly performed endoscopic interventions; M. Kurata performed histopathological diagnosis; and all authors reviewed the manuscript and provided final approval of the version to be submitted.

\section{Karger'"}




\section{Case Reports in Gastroenterology}

\section{References}

1 Ishii K, Matsuo K, Seki H, Yasui N, Sakata M, Shimada A, et al. Retroperitoneal Biloma due to Spontaneous Perforation of the Left Hepatic Duct. Am J Case Rep. 2016 Apr;17:264-7.

2 Freeland J. RUPTURE OF THE HEPATIC DUCT. Lancet. 1882;119(3062):731-2.

3 Lee HK, Han HS, Lee JH, Min SK. Nontraumatic perforation of the bile duct treated with laparoscopic surgery. J Laparoendosc Adv Surg Tech A. 2005 Jun;15(3):329-32.

4 Laway MA, Bakshi IH, Shah M, Paray SA, Malla MS. Biliary Peritonitis due to Spontaneous Perforation of Choledochus: A Case Report. Indian J Surg. 2013 Jun;75(S1 Suppl 1):96-8.

5 Chardot C, Iskandarani F, De Dreuzy O, Duquesne B, Pariente D, Bernard O, et al. Spontaneous perforation of the biliary tract in infancy: a series of 11 cases. Eur J Pediatr Surg. 1996 Dec;6(6):341-6.

6 Kerstein MD, McSwain NE. Spontaneous rupture of the common bile duct. Am J Gastroenterol. 1985 Jun;80(6):469-71.

7 Talwar N, Andley M, Ravi B, Kumar A. Spontaneous biliary tract perforations: an unusual cause of peritonitis in pregnancy. Report of two cases and review of literature. World J Emerg Surg. 2006 Jul;1(21):21.

8 Piotrowski JJ, Van Stiegmann G, Liechty RD. Spontaneous bile duct rupture in pregnancy. HPB Surg. 1990 Jul;2(3):205-9.

9 Sumer F, Kayaalp C, Karagül S, Ertugrul I, Yagci MA, Onur A. Case report of non-traumatic spontaneous intrahepatic bile duct rupture in an adult. Int J Surg Case Rep. 2016;21:104-6.

10 Kogure K, Kojima I, Kuwano H, Matsuzaki T, Yorifuji H, Takata K, et al. Reconfirmation of the anatomy of the left triangular ligament and the appendix fibrosa hepatis in human livers, and its implication in abdominal surgery. J Hepatobiliary Pancreat Sci. 2014 Dec;21(12):856-63.

11 Gao XH, Roberts A. The left triangular ligament of the liver and the structures in its free edge (appendix fibrosa hepatis) in Chinese and Canadian cadavers. Am Surg. 1986 May;52(5):246-52.

12 Champetier J, Davin JL, Letoublon C, Laborde Y, Yver R, Cousset F. Aberrant biliary ducts (vasa aberrantia): Surgical implications. Anatomia Clinica. 1982;4(2):137-45.

13 Katsuyoshi Ando HT. Eiichiro Ichiishi, Kiichi Sato. A recurrent case of Lemmel's syndrome improved by an additional endoscopic sphincterotomy. Progress of Digestive Endoscopy. 2015;86(1):208-9.

14 Ryozawa S, Itoi T, Katanuma A, Okabe Y, Kato H, Horaguchi J, et al. Japan Gastroenterological Endoscopy Society guidelines for endoscopic sphincterotomy. Digestive Endoscopy official journal of the Japan Gastroenterological Endoscopy Society. 2018 Mar;30(2):149-73. https://doi.org/10.1111/den.13001.

15 Deguchi I, Hayashi T, Takao M. [Severe coagulation abnormality during treatment for ischemic enteritis in an older patient taking a direct oral anticoagulant]. Nippon Ronen Igakkai Zasshi. 2019;56(1):74-8. 
Case Reports in Gastroenterology
Case Rep Gastroenterol 2021;15:53-61

(c) 2021 The Author(s). Published by S. Karger AG, Basel www.karger.com/crg

Fukui et al.: Spontaneous Bile Duct Rupture in the Left Triangular Ligament after EST

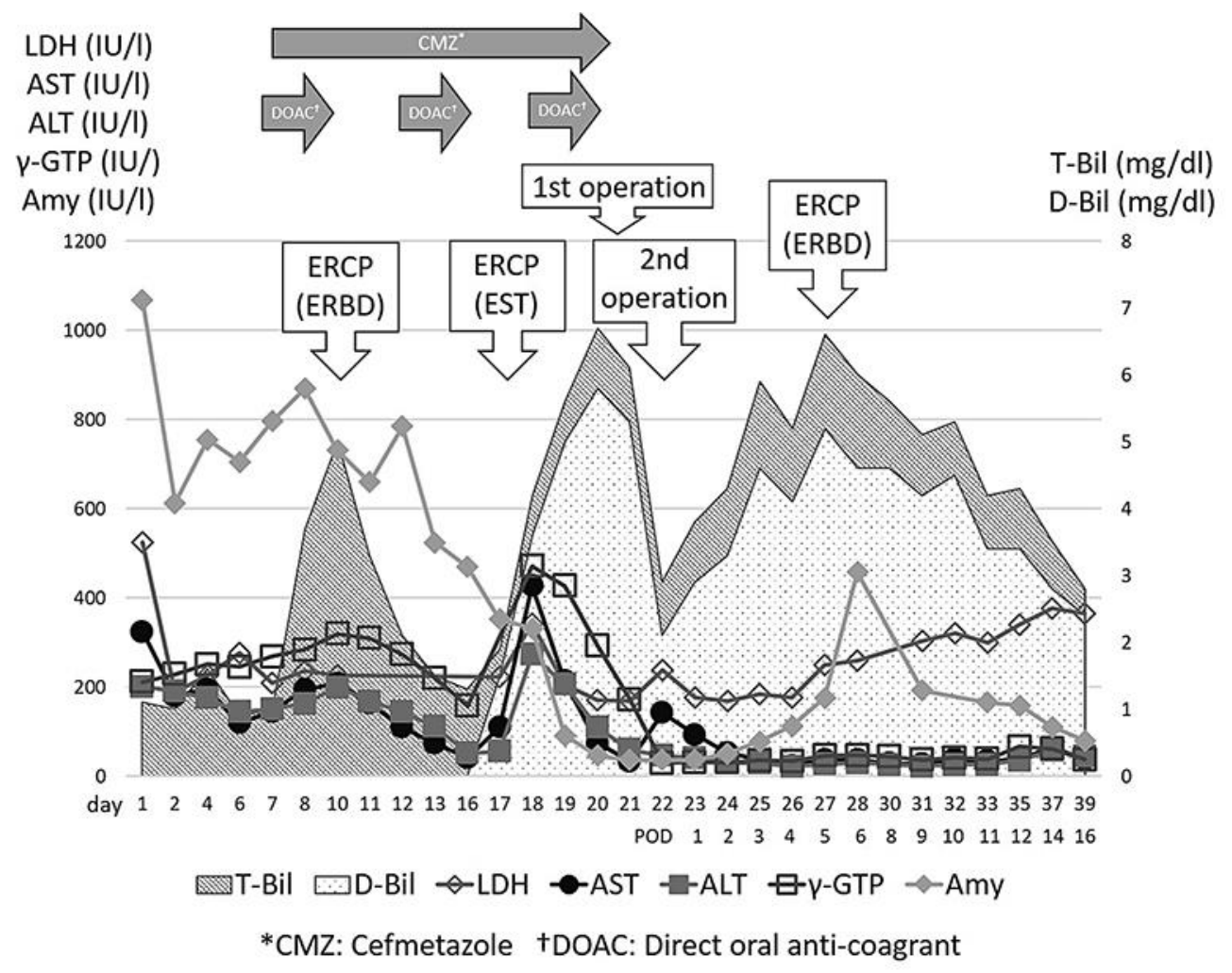

Fig. 1. Trends in hepatobiliary enzyme and bilirubin levels and clinical events during admission. 
Case Reports in Gastroenterology
Case Rep Gastroenterol 2021;15:53-61

DOI: 10.1159/000510932

(c) 2021 The Author(s). Published by S. Karger AG, Basel www.karger.com/crg

Fukui et al.: Spontaneous Bile Duct Rupture in the Left Triangular Ligament after EST
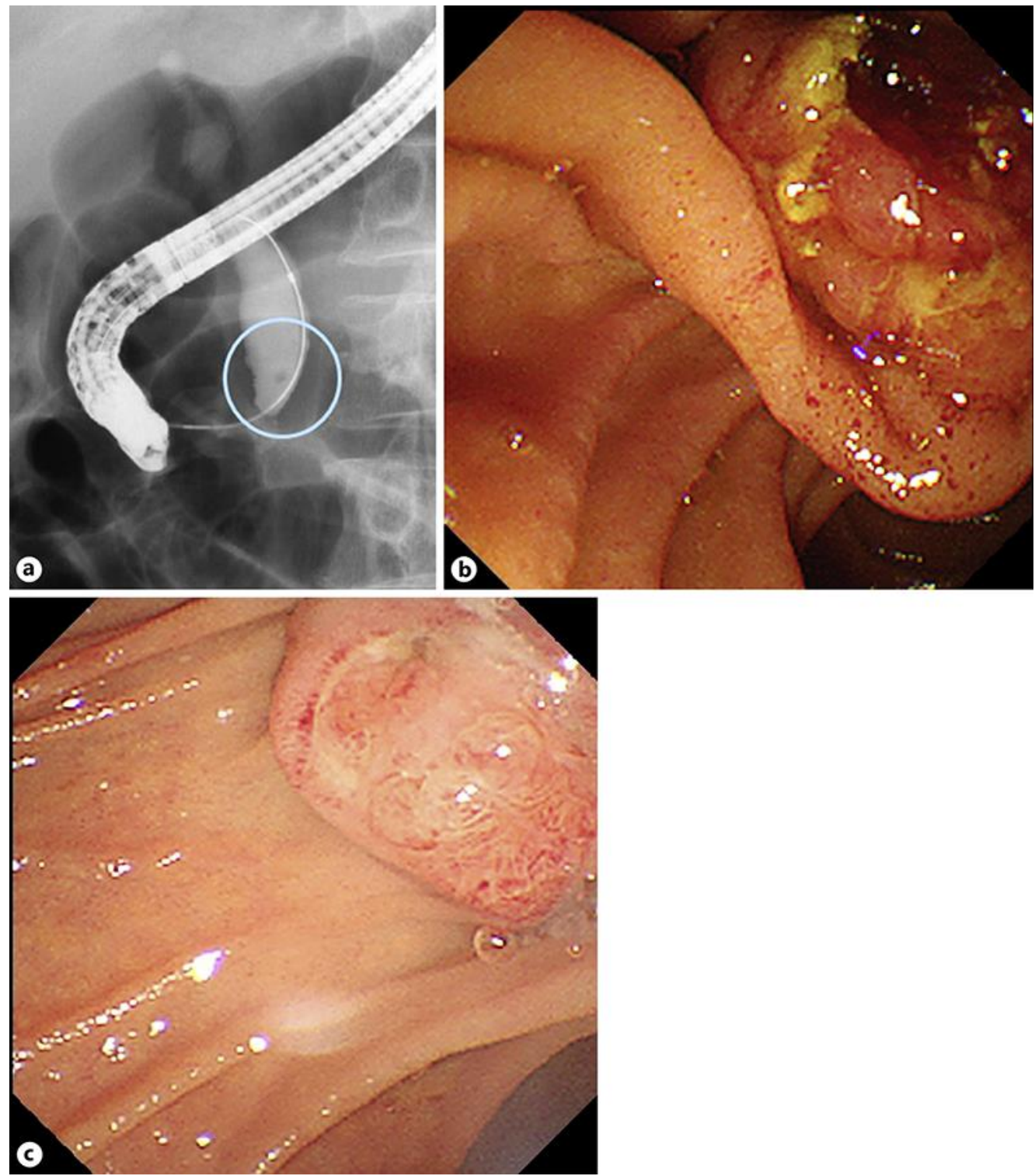

Fig. 2. a The first ERCP on day 11 revealed a defect, which indicated a stone in the common bile duct. b The findings of the second ERCP on day 18. Endoscopic sphincterotomy (EST) was performed during removal of the ERBD and the common bile duct stones using endoscopic papillary balloon dilatation (EPBD). c On postoperative day 5 , the appearance of the papilla of Vater (post EST) was normal.

\section{Karger'}




\section{Case Reports in Gastroenterology}
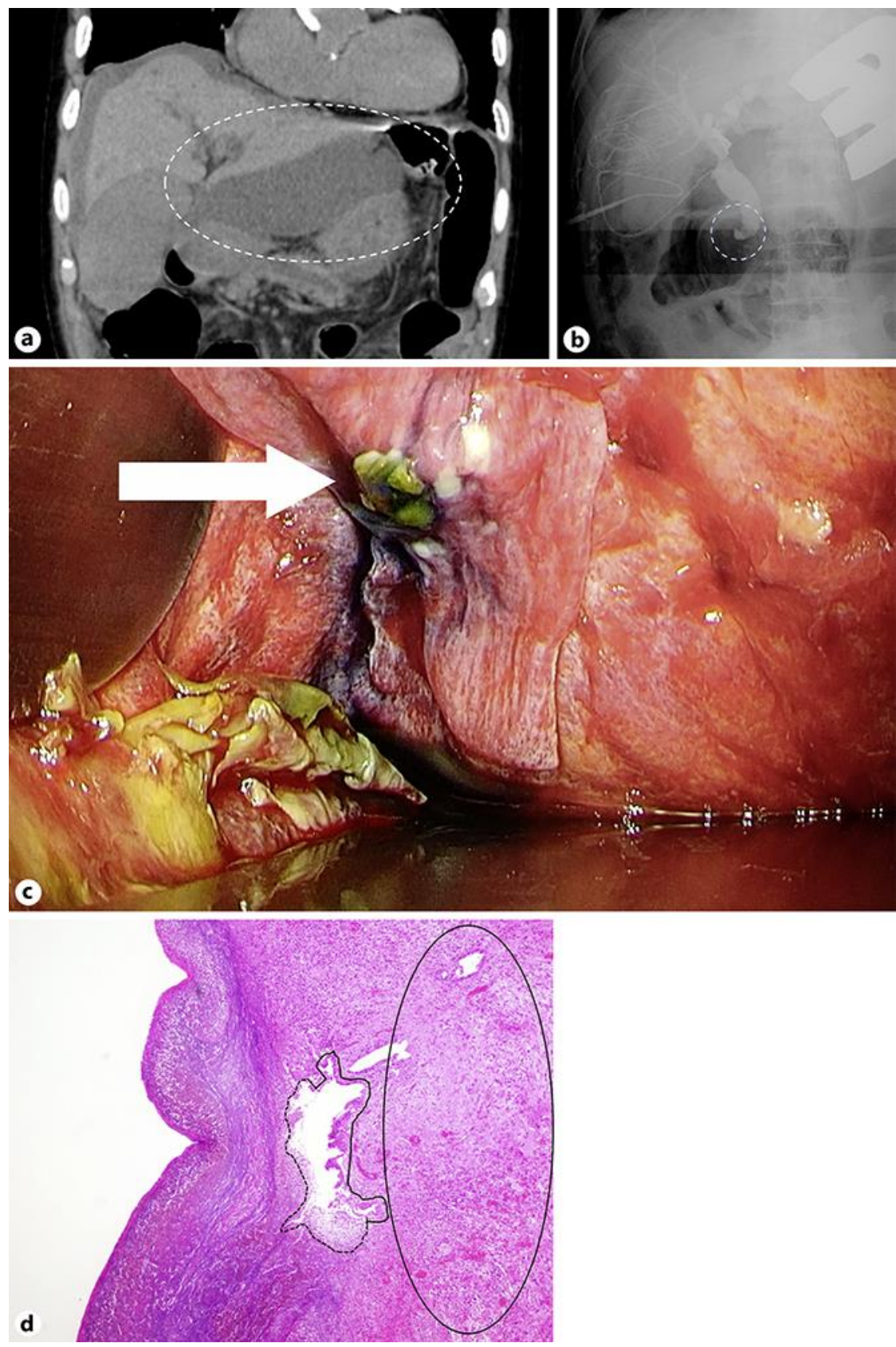

Fig. 3. a CT scan on day 21 showed a low density area that was $10 \mathrm{~cm}$ in diameter under the lateral segment of the liver (indicated by a broken line circle), which was larger compared with that on day 19, and ascites. b An intraoperative cholangiography with X-ray contrast medium in the first operation. The leak was not evident. There was no outflow of contrast medium into the duodenum (indicated by a broken line circle). c Through intraoperative cholangiography with dye injection, the perforation site was identified at the proximal side of the left triangular ligament (indicated by an arrow). $\mathbf{d}$ A microscopic image of the surgical specimen (200× magnification). The bold line indicates the wall of the bile duct. The broken line indicates the defect in the bile duct, which was assumed to be a perforation site. The encircled area indicates fibrous connective tissue, neutrophil infiltration, and fibrin deposition.

\section{Karger'}

